\title{
ATMOS stratospheric deuterated water and implications for troposphere-stratosphere transport
}

\author{
Elisabeth J. Moyer ${ }^{1}$, Fredrick W. Irion ${ }^{2}$, Yuk L. Yung ${ }^{1}$, and Michael R. \\ Gunson $^{3}$
}

\begin{abstract}
Measurements of the isotopic composition of stratospheric water by the ATMOS instrument are used to infer the convective history of stratospheric air. The average water vapor entering the stratosphere is found to be highly depleted of deuterium, with $\delta \mathrm{D}_{\mathrm{w}}$ of $670 \pm 80$ ( $67 \%$ deuterium loss). Model calculations predict, however, that under conditions of thermodynamic equilibrium, dehydration to stratospheric mixing ratios should produce stronger depletion to $\delta \mathrm{D}_{\mathrm{w}}$ of -800 to 900 ( $80-90 \%$ deuterium loss). Deuterium enrichment of water vapor in ascending parcels can occur only in conditions of rapid convection; enrichments persisting into the stratosphere require that those conditions continue to near-tropopause altitudes. We conclude that either the predominant source of water vapor to the uppermost troposphere is enriched convective water, most likely evaporated cloud ice, or troposphere-stratosphere transport occurs closely associated with tropical deep convection.
\end{abstract}

\section{Introduction}

The original Brewer-Dobson proposal for the circulation between troposphere and stratosphere involved slow ascent throughout the tropics, where the tropopause is highest and coldest, with the cell extending some distance into the troposphere [Brewer, 1949]. While subsequent research has confirmed the tropics as the location of most troposphere-stratosphere transport (abbrev. STE by convention) [e.g. Rosenlof and Holton, 1993], the speed and scale of the processes which move air across the tropopause and into the stratosphere are not yet well known. Tropopause temperature measurements suggest that the scale of STE may be more localized or episodic, since much of the tropical tropopause is too warm to freeze-dry air to observed stratospheric values [e.g. Frederick and Douglass, 1983]. Theories of STE now span a large range of temporal and spatial scales, from extremely rapid injection during isolated convective events which perturb the local temperature

\footnotetext{
${ }^{1}$ Division of Geological and Planetary Sciences, Caltech

${ }^{2}$ Department of Chemistry and Chemical Engineering, Caltech

${ }^{3}$ Jet Propulsion Laboratory
}

Copyright 1996 by the American Geophysical Union.

Paper number 96GL01489

0094-8534/96/96GL-01489\$05.00 structure $\left(1-10^{3} \mathrm{~km}^{2}\right)$ [e.g. Danielsen, 1982], to slower seasonal ascent over the coldest subregion of the trop$\operatorname{ics}\left(\approx 10^{7} \mathrm{~km}^{2}\right)$ [Newell and Gould-Stewart, 1981], with proposals for dehydration in the stratosphere itself during gravity-wave temperature fluctuations allowing ascent over even larger areas [Potter and Holton, 1994].

Upward mass transport in the underlying tropical troposphere, on the other hand, is believed to be highly localized and inhomogeneous, occurring primarily in convective cumulus towers [Riehl and Malkus, 1958]. STE may result simply from the extension of some cumuli into the stratosphere proper, or it may represent a qualitatively different process, with a transition between a middle troposphere in which upward motion is dominated by localized convection and an uppermost troposphere where slower mean motions are also important [e.g. Houze, 1989]. Observations of stratospheric water vapor content have not provided a means of resolving between these scenarios.

These scenarios differ in the process by which ascending air is dehydrated. During gradual ascent, dehydration must proceed by simple condensation and fallout of moisture. Dehydration in convective systems can be more complicated, since cumulus towers can carry with them enormous quantities of water as ice - neartropopause ice:vapor ratios can exceed 100 [Knollenberg et al., 1993] - and final water vapor mixing ratios may be net of both evaporation and condensation. Dehydration in stratospheric waves may also involve cycles of condensation and re-evaporation, but without significant transport of ice particles. Determination of not only the final water content of stratospheric air, but of the process by which that content is reached, can thus discriminate between transport scenarios, providing insight into the larger question of how air is exchanged between troposphere and stratosphere.

We propose that the isotopic composition of stratospheric water vapor is a useful tracer for this purpose, because it records the condensation and evaporation experienced by each air parcel that crosses the tropopause. Whenever several phases of water are present in thermodynamic equilibrium, the heavier isotopes partition preferentially into the condensed phases. As water condenses out of an air parcel, then, deuterated water is preferentially removed and the residual vapor is progressively lightened. The degree of preference, or fractionation factor, $\alpha$ ( $\left.\alpha \equiv \mathrm{D}: \mathrm{H}_{\text {condensate }} / \mathrm{D}: \mathrm{H}_{\text {vapor }}\right)$, is quite strong for deuterated water, with $\alpha$ ranging from 1.08 at room temperature to over 1.4 for ice condensation at the $\approx 190 \mathrm{~K}$ tropical tropopause [Majoube, 1971; Merlivat and Nief, 1967]. Stratospheric air, with 
a water vapor concentration four orders of magnitude less than that at sea surface, should be highly depleted in deuterium, but the exact degree of depletion will depend on the convective history of that air.

\section{ATMOS observations of $\delta \mathbf{D}_{\mathrm{w}}$}

Observations of stratospheric deuterated water by the Atmospheric Trace Molecular Spectroscopy (ATMOS) Fourier transform infrared spectrometer over the last decade provide the first large database of isotopic compositions that can be applied to the problem of STE. There have been few previous reported measurements of $\mathrm{HDO}$ and $\mathrm{H}_{2} \mathrm{O}$ in the lower stratosphere, where accurate spectroscopic measurement of both species is diffcult, with none in the tropics, the presumed source region for stratospheric air and water; nor have there been simultaneous measurements of $\mathrm{CH}_{4}$ and $\mathrm{CH}_{3} \mathrm{D}$. Observations in the mid-latitudes stratosphere have found water vapor strongly depleted of deuterium, but with $\delta \mathrm{D}_{\mathrm{w}}$ increasing with altitude from $\approx-600 \%$ at $20 \mathrm{~km}$ to $-350-450 \%$ at $35 \mathrm{~km}$. [Rinsland et al., 1984, 1991; Dinelli et al., 1991; Carli and Park, 1988; Pollock et al., 1980]. (Deuterium content is given in $\delta$ notation, where $\delta \mathrm{D}_{\mathrm{w}}$ is the fractional difference, in per mil, of the $\mathrm{D} / \mathrm{H}$ ratio of measured water from that of standard mean ocean water (SMOW), at $1.5576 \times 10^{-4}$ [Hageman et al., 1970].) This increase has been presumed to be the result of oxidation of isotopically heavier atmospheric methane. [e.g. Ehhalt, 1973; Rinsland et al., 1991].

This analysis uses data from all four ATMOS missions from 1985-1994, a total of 68 occultations in which $\mathrm{HDO}, \mathrm{H}_{2} \mathrm{O}$, and $\mathrm{CH}_{4}$ were retrieved (filters 2,9), and 67 in which $\mathrm{CH}_{3} \mathrm{D}$ was retrieved (filter 3 ). Only occulta-

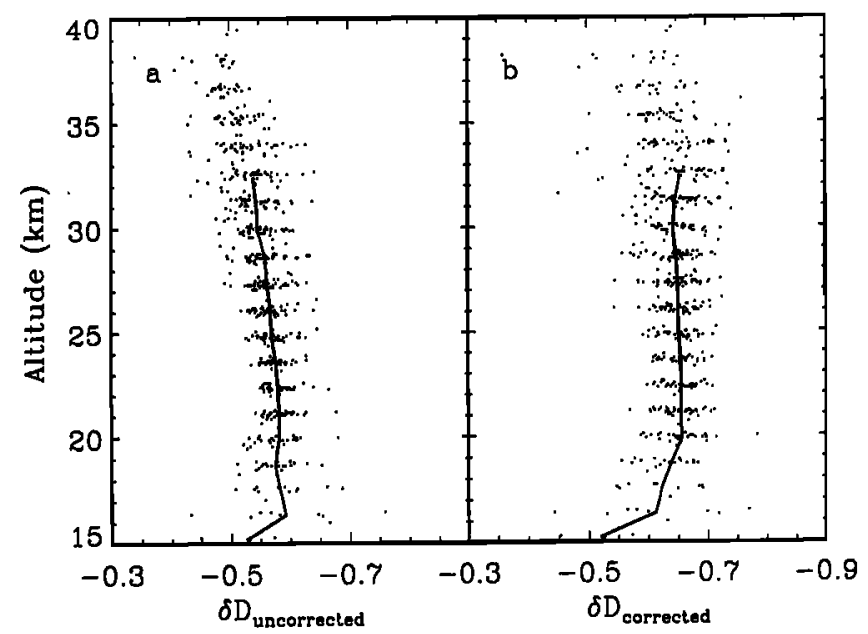

Figure 1. ATMOS measurements of the deuterium content of stratospheric water. The left panel shows uncorrected observations; the right panel the same data with the estimated contribution of $\mathrm{H}_{2} \mathrm{O}$ and HDO from methane oxidation subtracted. Data shown are those with error $\mathrm{H}_{2} \mathrm{O} \leq 10 \%$, error $\mathrm{CH}_{4} \leq 10 \%$, and error $\mathrm{HDO}$ $\leq 30 \%, \approx 75 \%$ of the total dataset. Solid lines represent weighted mean profiles from 15-32 km. Distribution $\sigma$ for corrected $\delta D_{w}$ is $35 \%$; total error with systematic errors is $80 \%$. tions in the polar vortices, where dehydration on polar stratospheric clouds produces additional isotopic effects, have been excluded. Latitudinal coverage is nearglobal (24\% tropical, $18 \%$ mid-latitudes, $58 \%$ high latitudes). The ATMOS instrument, coverage, and data reduction procedure are described in detail elsewhere [Gunson et al., 1996, and references therein].

Water vapor isotopic compositions are corrected for changes occurring in the stratosphere by subtraction of methane-derived contributions of $\mathrm{HDO}$ and $\mathrm{H}_{2} \mathrm{O}$ at each data point; conservation of hydrogen and deuterium between water and methane in the stratosphere is demonstrated from these same data by Irion et al. and Abbas et al. [1996]. Initial concentrations of $\mathrm{CH}_{4}$ and $\mathrm{CH}_{3} \mathrm{D}$ are taken as $1.7 \times 10^{-6}$ and $9.9 \times 10^{-10}$, respectively, from $W M O$ [1994] and the filter $3 \ln \left[\mathrm{CH}_{3} \mathrm{D}\right]$ : $\ln \left[\mathrm{CH}_{4}\right]$ relationship [Irion et al., 1996]. $\mathrm{CH}_{3} \mathrm{D}$ concentrations are inferred from observed $\mathrm{CH}_{4}$ in filters 2 and 9 using this relationship. This correction yields the isotopic composition of water as it first crosses the tropopause, with no assumptions as to the initial concentration of that water.

Figure 1 shows measurements of the isotopic composition of stratospheric water from all four ATMOS missions, before (1a) and after (1b) correction for methane contribution. After correction there is no trend in composition with altitude above $20 \mathrm{~km}$. Slight deviations below $20 \mathrm{~km}$ are most likely due to the increased error in retrieval of water concentrations. The mean stratospheric water is highly depleted, with a $\overline{\delta \mathrm{D}_{\mathrm{w}}}$ of -670 $\pm 80 \%$, or $67 \%$ loss of deuterium (weighted mean of all extravortex observations from $18-32 \mathrm{~km}$; error represents $1 \sigma$ of the distribution + systematic error.)

There is no significant variation in $\bar{\delta}_{w}$ with mission, filter, or latitude, over the 9 year span of these measurements, nor in comparison with previous measurements dating to 1980 [e.g. Pollock et al., 1980]. Mesoscale or seasonal variability in $\delta \mathrm{D}_{\mathrm{w}}$ of entering stratospheric air should be discernible only in the lower tropical stratosphere, where ATMOS HDO data is limited to only four occultations (28 observations). The distribution of $\delta \mathrm{D}_{\mathrm{w}}$ values in these data is similar to that of the whole dataset, a Gaussian distribution with a peak at $-680 \%$ and a width of $90 \%$, with no outliers that might suggest contributions from isotopically distinct processes. Although isentropic mixing should erase much spatial inhomogeneity, this consistency suggests that stratospheric water enters with a characteristic isotopic signature similar to the mean stratospheric value.

\section{Implications of stratospheric $\delta \mathbf{D}_{\mathrm{w}}$}

To explore the implications of the isotopic signature of stratospheric water, we have developed a multi-phase cloud model that computes isotopic trajectories during the ascent of air to the tropopause. The model represents the one-dimensional, pseudoadiabatic lifting of air parcels, with the concentrations and isotopic compositions of vapor, liquid, and ice tracked throughout. Air parcels are stepped upward until the water vapor mixing ratio equals the mean lower stratospheric value in 


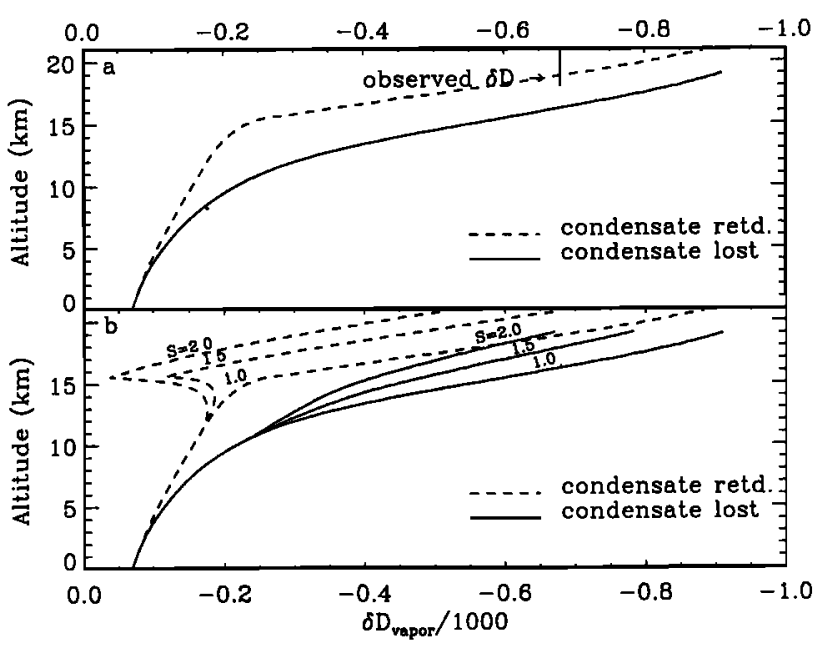

Figure 2. Model calculations showing the isotopic composition of water vapor during ascent to the stratosphere: upper panel, for conditions of thermodynamic equilibrium; lower panel, with fractionation factor modified by supersaturated conditions. Solid/dashed lines represent immediate removal/total retention of liquid condensate, and bracket the full range of $\delta \mathrm{D}$ values possible in these scenarios. The strong enhancements at $10-12 \mathrm{~km}$ in high- $S$ water-retaining cases occur because glaciation is allowed to proceed by evaporation of droplets and recondensation as ice: at high $S, \alpha_{\text {vapor-ice }}$ is less than $\alpha_{\text {vapor-liquid }}$ and deuterium is pumped into the vapor. Complete vapor deposition of ice is not realistic and is an endmember case only.

these data of $3.6 \mathrm{ppm}$. (Model results are robust with respect to this value; variations in water vapor of $\pm 20 \%$ produce only minor isotopic changes). Isotopic fractionation occurs during the initial evaporation of seawater, the condensation of liquid and ice, and the conversion of liquid to ice as the cloud glaciates. Cloud liquid is allowed to re-equilibrate with cloud vapor, while ice is effectively removed from the vapor. Free parameters of the model are: surface temperature and relative humidity, temperatures of the onset of ice nucleation and the completion of glaciation, the relative importance of droplet freezing to evaporation and re-deposition during glaciation, the degree of supersaturation over ice in the final stages of ascent, and the precipitation (or lack thereof) in all condensing stages. Although simplified, the model captures the full range of possible conditions for a simple convective updraft.

In the first set of model runs isotopic partitioning was assumed to occur at thermodynamic equilibrium in all stages, with the temperature dependence of $\alpha$ taken from Majoube [1971] and Merlivat and Nief [1967]. In these conditions, model-generated final isotopic compositions at the tropical tropopause in these conditions are all considerably lighter than observed stratospheric water (Figure 2a). Stratospheric water vapor is highly depleted of deuterium, but it is less depleted than would be expected given the extent of dehydration experienced. While at lower altitudes, where liquid is present, vapor isotopic compositions can be substantially altered by choice of model parameters, all trajectories converge during the nearly $7 \mathrm{~km}$ of ascent in ice-only conditions from the homogeneous freezing point of liquid water at $\approx 233 \mathrm{~K}$ to the tropical tropopause at $\approx 190 \mathrm{~K}$. Dehydration in those last kilometers strips out virtually all deuterium: vapor concentration must drop by a factor of over a hundred, with strong fractionation at $\alpha$ $=1.3-1.4$, so vapor $\mathrm{D} / \mathrm{H}$ must drop by over $80 \%$ over this altitude range alone. Even if no depletion occurred until the onset of ice condensation, the final $\delta \mathrm{D}$ under these conditions would still be less than -800 .

The deuterium content of stratospheric water can be increased only if we postulate that (1) air parcels in this $10-17 \mathrm{~km}$ region receive additional contributions from sources that are not in equilibrium with the vapor, or (2) isotopic fractionation is weaker than equilibrium values imply. For postulate (1), lofted cloud ice is the only plausible source of non-equilibrated water in the upper troposphere or lower stratosphere. While liquid water can rapidly exchange and equilibrate with its environment, the isotopic composition of ice remains essentially fixed [Jouzel and Merlivat, 1984]. Ice particles carried upwards from their altitudes of condensation thus preserve anomalously heavy isotopic compositions in relation to their surrounding vapor, and, if later evaporated, serve to enrich the vapor $\mathrm{D} / \mathrm{H}$ ratio.

The second postulate, that isotopic fractionation has been reduced, is possible during ice deposition in highly supersaturated air parcels, where kinetic effects prevent the vapor and condensate from achieving their equilibrium isotopic partitioning [Jouzel and Merlivat, 1984]. Figure 2b shows isotopic trajectories calculated using this kinetic fractionation, for a range of supersaturations $(S)$. Because the condensing material extracts less deuterium, the residual vapor remains heavier; at $S$ of 1.5 to 2 (150 - $200 \%)$, depending on convective parameters, sufficient deuterium is left at the tropopause to match the observed stratospheric isotopic composition.

Either of these scenarios is possible only in strong convective systems. Supersaturations of $1.5-2$ can be sustained only by updraft velocities typical of the strongest cumulus cores; in steady state, approximately $20-50 \mathrm{~m} / \mathrm{s}$ for the ice particle size distribution observed during the STEP campaign in tropical near-tropopause cloud systems [Knollenberg et al., 1993; Rogers and Yau, 1989; Pruppacher and Klett, 1980]. Ice crystal evaporation, on the other hand, can significantly alter the isotopic composition of vapor only if the ice crystals are substantially out of equilibrium with that vapor, i.e. if evaporation occurs at altitudes significantly higher than the level of condensation, again a condition possible only in strong convective updrafts. (Temperature fluctuations of 5-8 degrees in stratospheric waves can produce only minor enrichments.)

Deuterium enrichment by either of these processes must occur near the tropopause in order for some effect to persist into the stratosphere. Water vapor in a rising air parcel is depleted from its original composition to observed stratospheric values in less than $3 \mathrm{~km}$ of ascent at upper tropospheric temperatures, so non-equilibrium deuterium contributions must be occurring in the last 
$3 \mathrm{~km}$ beneath the tropopause. Most water entering the stratosphere must experience convective conditions to at least the uppermost troposphere.

\section{Conclusions}

ATMOS deuterated water data constrain the process of STE to one of two scenarios. In the first, STE is closely associated with deep convection. Actual crosstropopause transport may occur either as penetrative convection which deposits air above the tropopause or as more gradual ascent in and above mesoscale convective systems; in the latter case the convective systems contributing to STE must reach altitudes of at least 14 to $15 \mathrm{~km}$ (for a $17 \mathrm{~km}$ tropopause). In the second, STE occurs over wider parts of the tropics, less directly associated with convective systems, but here water in the uppermost troposphere consists almost exclusively of enriched water from convective systems, most likely evaporated cloud ice. Again, this evaporation must occur at $14-15 \mathrm{~km}$ altitude or higher.

Further observations in the tropical lower stratosphere and upper troposphere are necessary for discriminating between these possibilities. Isotopic data from the stratosphere alone may be sufficient to demonstrate whether the final dehydration of stratospheric air occurs in slow ascent rather than in convective penetration with admixture of evaporated ice, if a clear seasonal cycle in stratospheric $\delta \mathrm{D}_{\mathrm{w}}$ is detectable. Upper tropospheric data are necessary to determine spatial scales of transport. We conclude that a high priority should be placed on obtaining further tropical measurements of $\mathrm{HDO}$ and $\mathrm{H}_{2} \mathrm{O}$ at these altitudes, and that these observations should provide substantial additional insight into mechanisms of troposphere-stratosphere transport.

Acknowledgments. We thank Michael Brown for his comments and suggestions on this manuscript, and David Keith and Nilton Renno for useful discussions. EJM acknowledges the support of a National Science Foundation Graduate Fellowship and a NASA Global Change Graduate Fellowship. This research was supported in part by NASA grant NAGW-413 to the California Institute of Technology.

\section{References}

Abbas, M. M. et al., Seasonal variations of water vapor in the lower stratosphere inferred from ATMOS/ATLAS-3 measurements of $\mathrm{H}_{2} \mathrm{O}$ and $\mathrm{CH}_{4}$, Geophys. Res. Lett., this issue, 1996.

Brewer, A. W., Evidence for a world circulation provided by the measurements of helium and water vapour distributions in the stratosphere, Quart. J. R. Met. Soc., 75, $187,1949$.

Carli, B. and J. Park, Simultaneous measurement of minor stratospheric constituents with emission far-infrared spectroscopy, J. Geophys. Res., 93, 33851, 1988.

Danielsen, E. F., A dehydration mechanism for the stratosphere, Geophys. Res. Lett., 9, 605, 1982.

Dinelli, B. M. et al., Measurement of stratospheric distributions of $\mathrm{H}_{2}^{16} \mathrm{O}, \mathrm{H}_{2}^{18} \mathrm{O}, \mathrm{H}_{2}^{17} \mathrm{O}$, and $\mathrm{HD}^{16} \mathrm{O}$ from far-infrared spectra, J. Geophys. Res., 96, 7509, 1991.
Ehhalt, D. H. Methane in the atmosphere, in Carbon and the Biosphere, G. M. Woodwell and E. V. Pecan, eds., Atomic Energy Commission, 1973.

Frederick, J. E. and A. R. Douglass, Atmospheric temperatures near the tropical tropopause: temporal variations, zonal asymmetry, and implications for stratospheric water vapor, Mon. Weather Rev., 111, 1397, 1983.

Gunson, M. R. et al., The Atmospheric Trace Molecular Spectroscopy (ATMOS) experiment deployment on the ATLAS-3 space shuttle mission, Geophys. Res. Lett., this issue, 1996.

Hageman, R. et al., Absolute D/H ratio for SMOW, Tellus, 22, 712, 1970.

Houze, R. A., Observed structure of mesoscale convective systems and implications for large-scale heating, $Q . J . R$. Meteo. Soc., 115, 425, 1989.

Irion, F. W. et al., Stratospheric observations of $C_{3} D$ and HDO from ATMOS infrared solar spectra: enrichments of deuterium in methane and implications for HD, Geophys. Res. Lett., this issue, 1996.

Jouzel, J. and L. Merlivat, Deuterium and oxygen-18 in precipitation: modeling of the isotopic effects during snow formation, J. Geophys. Res., 89, 11749, 1984.

Knollenberg, R. G. et al., Measurements of high number densities of ice crystals in the tops of tropical cumulonimbus, J. Geophys. Res., 98, 8639, 1993.

Majoube, M., Fractionation of oxygen 18 and of deuterium between water and its vapor, J. Chem. Phys., 68, 1423, 1971.

Merlivat, L. and G. Nief, Isotopic fractionation of the solidvapor and liquid-vapor changes of state of water at temperatures below 0C, Tellus, 19, 122, 1967.

Newell, R. E. and S. Gould-Stewart, A stratospheric fountain? J. Atmos. Sci., 38, 2789, 1981.

Pollock, W. et al., Measurement of stratospheric water vapor by cryogenic collection, J. Geophys. Res., 85, 5555, 1980.

Potter, B. E. and J. R. Holton, The role of monsoon convection in dehydration of the lower tropical stratosphere, J. Atmos. Sci., 52, 1034, 1994.

Pruppacher, H. R. and J. D. Klett, Microphysics of clouds and precipitation, D. Reidel Co., 1980.

Riehl, H. and J. S. Malkus, On the heat balance in the equatorial trough zone, Geophysica, 6, 503, 1958.

Rinsland, C. P. et al., Stratospheric profiles of heavy water isotopes and $\mathrm{CH}_{3} \mathrm{D}$ from analysis of the ATMOS Spacelab 3 infrared solar spectra, J. Geophys. Res., 96, 1057, 1991.

Rinsland, C. P. et al., Simultaneous stratospheric measurements of $\mathrm{H}_{2} \mathrm{O}, \mathrm{HDO}$, and $\mathrm{CH}_{4}$ from balloon-borne and aircraft infrared solar absorption spectra and tunable diode laser laboratory spectra of HDO, J. Geophys. Res., 89, $7259,1984$.

Rogers, R. R. and M. K. Yau, A short course in cloud physics, Pergamon Press, 1989.

World Meteorological Organization, Scientific Assessment of Ozone Depletion, 1994.

E. J. Moyer and Y. L. Yung, Division of Geological and Planetary Sciences, Caltech, Pasadena, CA 91125 (email: moyer@earth1.gps.caltech.edu)

Fredrick W. Irion, Dept. of Chemistry and Chemical

Engineering, Caltech, Pasadena, CA 91125.

M. R. Gunson, Jet Propulsion Laboratory, Pasadena, CA 91109

(received November 3, 1995; revised January 23, 1996; accepted April 4, 1996.) 